\title{
Challenges on Induction of Broadly Neutralizing Antibodies for Optimization of HIV Vaccines Development and Vectored Immunoprophylaxis
}

\author{
Pankaj Kumar \\ University of Saskatchewan, Saskatoon, Canada \\ Email: pak100@mail.usask.ca, panky8@yahoo.com
}

Received November 7, 2012; revised December 12, 2012; accepted December 19, 2012

\begin{abstract}
Despite extensive research efforts, a preventive human immunodeficiency virus (HIV) vaccine remains one of the major challenges in the field of AIDS research. Experimental strategies which have been proven successful for other viral vaccines are not enough to tackle HIV-1 and new approaches to design effective preventive AIDS vaccines are of utmost importance. Due to enormous diversity among global circulating HIV strains, an effective HIV vaccine must elicit broadly protective antibodies based responses; therefore discovering new broadly neutralizing antibodies (bNAbs) against HIV has become major focus in HIV vaccine research. However further understanding of the viral targets of such antibodies and mechanisms of action of bNAbs is required for advancement of HIV vaccine research. This technical note discusses our current knowledge on the bNAbs and immunoprophylaxis using viral vectors with their relevance in designing of new candidates to HIV-1 vaccines.
\end{abstract}

Keywords: HIV; AIDS; Broadly Neutralizing Antibodies (bNAbs); Vectored Immunoprophylaxis

\section{Introduction}

Despite years of research efforts, yet there is no vaccine that can establish protective immunity against HIV. The immune system generates robust adaptive immune responses (cellular and humoral) against the HIV virus, which are considered critical in either preventing or controlling the infection, and are therefore of great interest to AIDS vaccine researchers. Although several vaccine approaches tested till date have been able to enhance the magnitude of the immune responses to HIV infection, however most of these responses are by and large unsuccessful to be both effectively antiviral and targeted to prevent the emergence of fully functional escape variants. Nonetheless, both B and T cells still considered to play a critical role in controlling HIV infection and therefore an integral part towards development of an AIDS vaccine.

The Merck/HIV Vaccine Trials Network (V520MRKrAd5), called STEP, started in late 2004 and was terminated in September 2007. The aim of the STEP trial was to generate a potent HIV-specific T-cell based response; even though majority of vaccinated subjects in this trial developed both CD4+ and CD8+ T-cell responses, generated immune responses were not only ineffective but also vaccination appeared associated with an increased susceptibility to HIV infection in some recipients $[1,2]$. One of the major issues involved in
MRKrAd5 vaccine was due to high prevalence of preexisting neutralizing antibodies (NAbs), against adenovirus serotype 5 (Ad5), which was associated with an obstruction to the development of effective $\mathrm{T}$ cell response against Gag, Pol, and Nef of HIV antigen [1,2]. Failure of this much-publicised HIV-1 STEP trial has not only created phenomenal discussions among scientific community but also questions were raised of whether or not to pursue the development of T-cell-based HIV-1 vaccines. However several recent studies have shown that vaccine-induced $\mathrm{T}$ cell responses can control replication of both the acute phase and chronic phase of SIV replication using both homologous and heterologous challenges [3,4]. Recently Picker et al. (2011) have shown, for the first time, that SIV vaccine that includes rhesus cytomegalovirus (RhCMV) vectors, generates indefinitely persistent, high-frequency, SIV-specific effector memory T-cell responses at potential sites of SIV replication in rhesus macaques and effectively control high- ly pathogenic SIV (MAC239) infection early after mucosal challenge [5]. This report clearly demonstrates that it is possible to make a $\mathrm{T}$ cell-based vaccine, however a combination of both vaccine-induced antibodies and $\mathrm{T}$ cells would be optimal.

HIV envelope (Env) is known to be primary target for HIV-1 specific antibodies, however a major challenge for 
vaccine design is the extensive diversity found in Env glycoprotein. To cover the immense variability of HIV-1, vaccine eliciting neutralizing antibodies would need to be broadly reactive. Therefore targeting conserved sites on Env, for instance, functionally conserved CD4 binding site (CD4bs) on the Env, gp120, suggested being one potential means to elicit more broadly neutralizing antibodies (bNAbs) responses. Additionally the envelope glycoproteins gp120 and gp41 which are the main targets for neutralizing antibodies are partially protected by N-linked glycans and other structurally-imposed constraints, which limit antibody access to potential neutralization epitopes, reside within these regions. Although most antibodies induced during infection are non-neutralizing or strain specific, recent studies indicate that about $25 \%$ of HIV-1-infected patients produce bNAbs [6] and these antibodies have varying epitope specificities that could lead for multidirectional vaccine design. Therefore the ability to elicit broadly neutralizing antibody responses against HIV-1 has been crucial for a prophylactic HIV-1 vaccine development. Although there is not yet any successful HIV vaccine to establish protective immunity, Thai Phase III HIV vaccine clinical trial, also known as RV144, which tested the "prime-boost" combination of two vaccines: ALVAC® HIV vaccine (the prime) and AIDSVAX ${ }^{\circledR} \mathrm{B} / \mathrm{E}$ vaccine (the boost) has been first to show some modest efficacy against acquisition of infection [7]. Importantly, in this trial protection was associated with bNAbs directed against the V2 domain in the HIV envelope protein. Therefore to induce higher level of protection against HIV infection, the involvement of bNAbs is considered to be most essential.

So far a number of bNAbs have been successfully isolated that recognize various conserved regions of Env. For example, monoclonal antibodies VRC01-VRC03 and VRC-PG04 targets CD4bs on gp120 with strong bNAbs activity [8-10]. However with a slightly modified approach adopted by SChied et al. [11], many new bNAbs were expressed including very potent 3BNC117, 3BNC60 and NIH45-46. More recently Walker et al. discovered bNAbs against novel epitopes, using an approach of non specific high throughput memory B cell culture [12]. Thereafter secreted antibodies were tested against panel of HIV-1 variants. Using this approach, excellent bNAbs- PG9 and PG 16 were generated, which are trimer specific in conserved region of variable V2 and V3 loops of gp120 [13]. Very recently another group of PGT antibodies are discovered that react with epitopes near the base of V3 loop [13]. Table 1 describes epitope specificties of bNAbs to neutralizing HIV envelope. Although several new bNAbs candidates are discovered in recent years, the overall number of existing bNAbs with a relatively broad neutralization profile is still very limited. Moreover, bNAbs generated so far, are of variable
Table 1. Epitope specificity of bNAbs to neutralizing HIV envelope.

\begin{tabular}{cc}
\hline Epitope Specificities & bNAbs \\
\hline CD4-binding site on gp120 & B12, HJ16, 3BNC60, \\
& 3BNC117, VRC01-VRC03 and \\
GRC-PG04 \\
Glycan-specific & 2G12, PGT121-123, 125-128, \\
V1, V2, V3 loop on gp120 & PG9, PG16 and PGT141-145 \\
MPER & 2F5, 4E2 and Z13 \\
\hline
\end{tabular}

potency, with most effective against no more than $40 \%$ $50 \%$ of viral clades. Therefore further knowledge of the fine specificities of bNAbs such as, their characteristics, mode of instillation, are required in order to design efficacious vaccines. In this report certain important conditions are discussed that would be required to translate bNAbs into optimal immunogen.

\section{Identification of New Epitope Specificities}

In order to find even more potentially conserved regions within the virus envelope, extensive epitope mapping of broadly neutralizing activity in sera of patients with bNAbs would reveal different antibody specificities. Interestingly bNAbs activity in "elite neutralizers" are restricted to one or two epitope specificities with conserved regions of the V1, V2 and V3 loops or at CD4bs, therefore identifying individuals with new epitope specificities would narrow the number of individuals to isolate for new bNAbs. Furthermore, determination of specificities and molecular origin of bNAbs in diverse population around the globe would provide valuable clues for vaccine design. Moreover since most bNAbs, with the exception of the Walker et al. [12], are exclusively isolated from clade B virus-infected donors, and therefore new bNAbs from diverse clads of HIV-1-infected donors need to be isolated. In addition, screening of appropriate Env immunogen using high throughput such as ex vivo lymphoid tissue equivalent culture systems, $\left(\right.$ MIMIC $^{\mathrm{TM}}$-sanofi) would allow to screen induced antibodies with better quality of humoral response prior to human trials (http://www.vaxdesign.com/mimic-technology).

\section{Improved Cleaved, Trimeric, Functional Env Immunogen}

A key question is concerning the optimal form of envelope glycoprotein for inducing HIV-1 specific bNAbs. Since gp120 contains most of the neutralizing epitopes and monomeric gp120 is relatively easy to manufacture; however two early clinical trials using gp120 as subunit vaccine have failed to provide any protection. Although the recent RV144 trial priming with ALVAC vector pro- 
vided 31\% efficacy [7], however there are still many concerns for its use as an immunogen. Recently Sundling et al. (2010) reported robust Env-specific memory B cell responses with after trimer (gp140 trimer) inoculation in rhesus macaques that was superior to monomeric Env immunization (in human) [14]. Results of Kovacs et al. (2012) further supported the concept that HIV-1 trimers (stable gp140 trimer) more accurately mimic the antigenic properties of the native envelope spike on the surface of virions than gp120 monomers and thus could be better immunogen [15]. Therefore generating improved trimer immunogens that closely mimic the native functional spikes on the HIV-1 virions would be an important step toward an effective HIV-1 vaccine. Bimal et al. (2011) demonstrated that since uncleaved Env trimers expose for many more non-neutralizing epitopes than cleaved counterparts, Env cleavage should be included in a soluble trimeric immunogen; suggesting that full potential of cleaved, trimeric functional Env need to be further evaluated [16]. In addition, it is important to understand the mechanism of neutralization by gp41-directed neutralizing antibodies for better immunogen design. Additionally, biophysical, antigenic and immunogenicity study of these Env-based immunogens would provide relevant and critical information to forward HIV-1 vaccine development.

\section{Optimized Immunoprophylaxis Using Viral Vectors Encoding Broadly Neutralizing Antibodies against HIV}

Although several bNAbs have been extensively characterized, it largely remains unclear how to elicit these antibodies in the broader population. Most of the previous attempts demonstrated that direct administration of bNAbs fails to provide any long-term protection until repeated injections. Moreover although bNAbs can be directly installed into the bloodstream by methods such as infusion, however it would be impractical for HIV in a prophylactic setting [17]. Therefore, viral vectors were explored that could have potential to provide a sustained supply of neutralizing antibodies. However initial efforts were unsuccessful for HIV due to insufficient transduction by viral vectors and low levels of transgene expression [17]. However recently Balazs et al. [18] demonstrated a successful proof-of-concept, with recombinant adeno-associated virus (rAAV) vector encoding one of several different bNAbs; a perfect alternative to immunization. Importantly, passive administration of bNAbs offers several distinct advantages compared to a conventional vaccine approach, for instance it circumvents requirement of discovering and producing appropriate antigen and immediately direct the immune system for production of these antibodies [17]. Although Balazs et al. findings demonstrate preclinical application and therefore usual relevance of mouse model vs. human studies and AAV safety issues remains $[19,20]$ nonetheless this finding opens up an exciting and novel way to generate anti-HIV immunity outside of the scope of conventional vaccines that could have direct implications for translation to human studies.

After failure of STEP trial due to pre-existing human adenovirus (Ad5) immunity, significant progress has been made in the development of novel Ad vectors based on less prevalent human Ad serotypes including rAD26 and rAD35and nonhuman Ad [21-23]. For instance, in a recent phase I, placebo-controlled trial, the safety and immunogenicity of two recombinant replication defective adenovirus serotype 35 (Ad35) vectors were reported promising, while Ad35 neutralizing titers remained low after the second vaccination [24]. To increase immunogenicity, non-replicating vaccines (for e.g. plasmid DNA) are usually combined in a prime-boost regimen. While simple vaccine modalities are quite efficient in priming, more complex vectors such as poxviruses and adenoviruses have been excellent in boosting [25-27]. Currently, numerous prime-boost regimens are in both preclinical and clinical development [25-27], however by and large the RV144 trial in Thailand has been the most successful HIV vaccine trial till date. During the three-year monitoring period, RV144 demonstrated an estimated $31 \%$ reduction in HIV infections in the vaccinees compared to the placebo group. The recent work by kim et al. (2012) demonstrated that genetic signatures of RV144 vaccination in V2, complement the finding of an association between high V1/V2-binding antibodies and reduce risk of HIV-1 acquisition, and provide evidence that vaccine-induced V2 responses plausibly had a role in the partial protection conferred by the RV144 regimen [28, 29]. Though, different analyses of the RV144 data are conflicting, this trial clearly demonstrated that this vaccine regimen was safe and modestly effective, representing a significant scientific achievement and important implications towards design of future HIV vaccines and how they need to be tested; nonetheless, additional research is needed to better understand how this vaccine regimen reduced the risk of HIV infection

(http://www.hivresearch.org).

In the recent past, vectored immunoprophylaxis has emerged as one of the most promising technologies to install bNAbs and its knowledge base is consistently expanding. Exploring potential of newer vectored vaccine system (in particular replication-competent) such as nonhuman adenovirus, modified vaccine virus (MVA) and AAV would not only provide an effective strategy for circumvention of adenoviral vector immunity, but also would allow high throughput library screening and rapid assessment of the candidate vaccines for animal studies. 


\section{REFERENCES}

[1] S. P. Buchbinder, D. V. Mehrotra, A. Duerr, D. W. Fitzgerald, R. Mogg, D. Li, P. B. Gilbert, J. R. Lama, M. Marmor, C. D. Rio, M. J. McElrath, D. R. Casimiro, K. M. Gottesdiener, J. A. Chodakewitz, L. Corey and M. N. Robertson, "The Step Study Protocol Team. Efficacy Aassessment of a Cell-Mediated Immunity HIV-1 Vaccine (the Step Study): A Double-Blind, Randomised, Placebo-Controlled, Test-of-Concept Trial,” Lancet, Vol. 372, No. 9653, 2008, pp. 1881-1893. doi:10.1016/S0140-6736(08)61591-3

[2] M. J. McElrath , S. C. De Rosa, Z. Moodie, S. Dubey, L. Kierstead, H. Janes, O. D. Defawe, D. K.Carter , J. Hural, R. Akondy, S. P. Buchbinder, M. N. Robertson, D. V. Mehrotra, S. G. Self, L. Corey, J. W. Shiver and D. R. Casimiro, "Step Study Protocol Team. HIV-1 VaccineInduced Immunity in the Test-of-Concept Step Study: A Case-Cohort Analysis,” Lancet, Vol. 372, No. 9653, 2008, pp. 1894-1905. doi:10.1016/S0140-6736(08)61592-5

[3] J. Liu, K. L. O’Brien, D. M. Lynch, N. L.Simmons, A. La Porte, A. M. Riggs, P. Abbink, R. T. Coffey, L. E. Grandpre, M. S. Seaman, G. Landucci, D. N. Forthal, D. C. Montefiori, A. Carville, K. G. Mansfield, M. J. Havenga, M. G. Pau, J. Goudsmit and D. H. Barouch, "Immune Control of an SIV Challenge by a T-Cell-Based Vaccine in Rhesus Monkeys,” Nature, Vol. 457, No. 7225, 2009, pp. 87-91. doi:10.1038/nature07469

[4] S. G. Hansen, C. Vieville, N. Whizin, L. Coyne-Johnson, D. C. Siess, D. D. Drummond, A. W. Legasse, M. K. Axthelm, K. Oswald, C. M.Trubey, M. Piatak Jr, J. D. Lifson, J. A. Nelson, M. A.Jarvis and L. J. Picker, "Effector Memory T Cell Responses Are Associated with Protection of Rhesus Monkeys from Mucosal Simian Immunodeficiency Virus Challenge,” Nature Medicine, Vol. 15, No. 3, 2009, pp. 293-299. doi:10.1038/nm.1935

[5] S. G. Hansen, J. C. Ford, M. S. Lewis, A. B Ventura, C. M. Hughes, L. Coyne-Johnson, N. Whizin, K. Oswald, R. Shoemaker, T. Swanson, A. W. Legasse, M. J. Chiuchiolo, C. L. Parks, M. K. Axthelm, J. A. Nelson, M. A. Jarvis, M. Piatak Jr, J. D. Lifson and L. J. Picker, "Profound Early Control of Highly Pathogenic SIV by an Effector Memory T-Cell Vaccine,” Nature, Vol. 473, No. 7348, 2011, pp. 523-527. doi:10.1038/nature10003

[6] L. Stamatatos, L. Morris, D. R. Burton and J. R. Mascola, "Neutralizing Antibodies Generated during Natural HIV-1 Infection: Good News for an HIV-1 Vaccine?" Nature Medicine, Vol. 15, No. 8, 2009, pp. 866-870.

[7] S. Rerks-Ngarm, P. Pitisuttithum, S. Nitayaphan, J. Kaewkungwal, J. Chiu, R. Paris, N. Premsri, C. Namwat, M. de Souza, E. Adams, M. Benenson, S. Gurunathan, J. Tartaglia, J. G.McNeil, D. P. Francis, D. Stablein, D. L. Birx, S. Chunsuttiwat, C. Khamboonruang, P. Thong-charoen, M. L. Robb, N. L. Michael, P. Kunasol and J. H. Kim, "MOPH-TAVEG Investigators. Vaccination with ALVAC and AIDSVAX to Prevent HIV-1 Infection in Thailand,” The New England Journal of Medicine, Vol. 361, No. 23, 2009, pp. 2209-2220.

doi:10.1056/NEJMoa0908492

[8] T. Zhou, I. Georgiev, X. Wu, Z. Y. Yang, K. Dai, A.
Finzi, Y. D. Kwon, J. F. Scheid, W. Shi, L. Xu, Y. Yang, J. Zhu, M. C. Nussenzweig, J. Sodroski, L. Shapiro, G. J. Nabel, J. R. Mascola and P. D. Kwong, "Structural Basis for Broad and Potent Neutralization of HIV-1 by Antibody VRC01,” Science, Vol. 329, No. 5993, 2010, pp. 811-817. doi:10.1126/science.1192819

[9] X. Wu, Z. Y.Yang, Y. Li, C. M. Hogerkorp, W. R. Schief, M. S. Seaman, T. Zhou, S. D. Schmidt, L. Wu, L. Xu, N. S. Longo, K. McKee, S. O’Dell, M. K. Louder, D. L. Wycuff, Y. Feng, M. Nason, N. Doria-Rose, M. Connors, P. D. Kwong, M. Roederer, R. T.Wyatt, G. J. Nabel and J. R. Mascola, "Rational Design of Envelope Identifies Broadly Neutralizing Human Monoclonal Antibodies to HIV-1,” Science, Vol. 329, No. 5993, 2010, pp. 856-561. doi:10.1126/science.1187659

[10] X. Wu, T. Zhou, J. Zhu, B. Zhang, I. Georgiev, C. Wang, X. Chen, N. S. Longo, M. Louder, K. McKee, S. O’Dell, S. Perfetto, S. D. Schmidt, W. Shi, L. Wu, Y. Yang, Z. Y. Yang, Z. Yang, Z. Zhang, M. Bonsignori, J. A. Crump, S. H. Kapiga, N. E. Sam, B. F. Haynes, M. Simek, D. R. Burton, W. C. Koff, N. A. Doria-Rose, M. Connors, J. C. Mullikin, G. J. Nabel, M. Roederer, L. Shapiro, P. D. Kwong and J. R. Mascola, "Focused Evolution of HIV-1 Neutralizing Antibodies Revealed by Structures and Deep Sequencing,” Science, Vol. 333, No. 6049, 2011, pp. 1593-1602. doi:10.1126/science.1207532

[11] J. F. Scheid, H. Mouquet, B. Ueberheide, R. Diskin, F. Klein, T. Y. Oliveira, J. Pietzsch, D. Fenyo, A. Abadir, K. Velinzon, A. Hurley, S. Myung, F. Boulad, P. Poignard, D. R. Burton, F. Pereyra, D. D. Ho, B. D. Walker, M. S. Seaman, P. J. Bjorkman, B. T. Chait and M. C. Nussenzweig, "Sequence and Structural Convergence of Broad and Potent HIV Antibodies That Mimic CD4 Binding," Science, Vol. 333, No. 6049, 2011, pp. 1633-1637. doi:10.1126/science.1207227

[12] L. M. Walker, S. K. Phogat, P. Y. Chan-Hui, D. Wagner, P. Phung, J. L. Goss, T. Wrin, M. D. Simek, S. Fling, J. L. Mitcham, J. K. Lehrman, F. H. Priddy, O. A. Olsen, S. M. Frey and P. W. Hammond, S. Kaminsky, T. Zamb, M. Moyle, W. C. Koff, P. Poignard and D. R. Burton, "Broad and Potent Neutralizing Antibodies from an African Donor Reveal a New HIV-1 Vaccine Target,” Science, Vol. 326, No. 5950, 2009, pp. 285-289. doi:10.1126/science.1178746

[13] L. M. Walker, M. Huber, K. J. Doores, E. Falkowska, R. Pejchal, J. P. Julien, S. K. Wang, A. Ramos, P. Y. Chan-Hui, M. Moyle, J. L. Mitcham, P. W. Hammond, O. A. Olsen, P. Phung, S. Fling, C. H. Wong, S. Phogat, T. Wrin and M. D. Simek, W. C. Koff, I. A. Wilson, D. R. Burton and P. Poignard, "Broad Neutralization Coverage of HIV by Multiple Highly Potent Antibodies,” Nature, Vol. 477, No. 7365, 2011, pp. 466-70. doi:10.1038/nature10373

[14] C. Sundling, M. N. Forsell, S. O’Dell, Y. Feng, B. Chakrabarti, S. S. Rao, K. Loré, J. R. Mascola, R. T. Wyatt, I. Douagi and G. B. Karlsson Hedestam Soluble HIV-1 Env Trimers in Adjuvant Elicit Potent and Diverse Functional B Cell Responses in Primates,” Journal of Experimental Medicine, Vol. 207, No. 9, 2010, pp. 2003-2017. doi:10.1084/jem.20100025

[15] J. M. Kovacs, J. P. Nkolola, H. Peng, A. Cheung, J. Perry, 
C. A. Miller, M. S. Seaman, D. H. Barouch and B. Chen, "HIV-1 Envelope Trimer Elicits More Potent Neutralizing Antibody Responses than Monomeric gp120,” Proceedings of the National Academy of Sciences of the United States of America, Vol. 109, No. 30, 2012, Article ID: 12111. doi:10.1073/pnas.1204533109

[16] B. K. Chakrabarti, M. Pancera, S. Phogat, S. O’Dell, K. McKee, J. Guenaga, J. Robinson, J. Mascola and R. T. Wyatt, "HIV Type 1 Env Precursor Cleavage State Affects Recognition by Both Neutralizing and Nonneutralizing gp41 Antibodies," AIDS Research and Human Retroviruses, Vol. 27, No. 8, 2011, pp. 877-887. doi:10.1089/aid.2010.0281

[17] M. A. Liu, "Gene-Based Passive Antibody Protection from HIV,” Nature Biotechnology, Vol. 30, No. 2, 2012, pp. 156-157. doi:10.1038/nbt.2114

[18] A. B. Balazs, J. Chen, C. M. Hong, D. S. Rao, L. Yang and D. Baltimore, "Antibody-Based Protection against HIV Infection by Vectored Immunoprophylaxis,” Nature, Vol. 481, No. 7379, 2011, pp. 81-84. doi:10.1038/nature10660

[19] S. L. Murphy, H. Li, F. Mingozzi, D. E. Sabatino, D. J. Hui, S. A. Edmonson and K. A. High, "Diverse IgG Subclass Responses to Adeno-Associated Virus Infection and Vector Administration,” Journal of Medical Virology, Vol. 81, No. 1, 2009, pp. 65-74. doi:10.1002/jmv.21360

[20] G. L. Rogers, A. T. Martino, G. V. Aslanidi, G. R. Jayandharan, A. Srivastava and R. W. Herzog, "Innate Immune Responses to AAV Vectors,” Frontiers in Microbiology, Vol. 2, 2011, p. 194.

[21] S. Ratto-Kim, J. R. Currier, J. H. Cox, J. L.Excler, A. Valencia-Micolta, D. Thelian, V. Lo, E. Sayeed, V. R. Polonis, P. L. Earl, B. Moss, M. L. Robb, N. L. Michael, J. H. Kim and M. A. Marovich, "Heterologous PrimeBoost Regimens Using rAd35 and rMVA Vectors Elicit Stronger Cellular Immune Responses to HIV Proteins than Homologous Regimens,” PLoS One, Vol. 7, No. 9, 2012, p. e45840. doi:10.1371/journal.pone.0045840

[22] S. A. Brown, S. L. Surman, R. Sealy, B. G. Jones, K. S. Slobod, K. Branum, T. D. Lockey, N. Howlett, P. Freiden, P. Flynn and J. L. Hurwitz, "Heterologous Prime-Boost HIV-1 Vaccination Regimens in Pre-Clinical and Clinical Trials,” Viruses, 2010; Vol. 2, No. 2, pp. 435-467. doi:10.3390/v2020435

[23] C. Li, Z. Shen, X. Li, J. Bai, L. Zeng, M. Tian, Y. J. Song, M. Ye, S. Du, D. Ren, C. Liu, N. Zhu, D. Sun, Y. Li and N. Jin, "Protection against SHIV-KB9 Infection by Combining rDNa and rFPV Vaccines Based on HIV Multiepitope and P24 Protein in Chinese Rhesus Macaques,” Clinical and Developmental Immunology, Vol. 2012, 2012, Article ID: 958404.

[24] M. C. Keefer, J. Gilmour, P. Hayes, D. Gill, J. Kopycinski, H. Cheeseman, M. Cashin-Cox, M. Naarding, L. Clark, N. Fernandez, C. A. Bunce, C. M. Hay, S. Welsh, W. Komaroff, L. Hachaambwa, T. Tarragona-Fiol, E.
Sayeed, D. Zachariah, J. Ackland, K. Loughran, B. Barin, E. Cormier, J. H. Cox, P. Fast and J. L. Excler, “A Phase I Double Blind, Placebo-Controlled, Randomized Study of a Multigenic HIV-1 Adenovirus Subtype 35 Vector Vaccine in Healthy Uninfected Adults,” PLoS One, Vol. 7, No. 8, 2012, p. e41936. doi:10.1371/journal.pone.0041936

[25] T. W. Geisbert, M. Bailey, L. Hensley, C. Asiedu, J. Geisbert, D. Stanley, A. Honko, J. Johnson, S. Mulangu, M. G. Pau, J. Custers, J. Vellinga, J. Hendriks, P. Jahrling, M. Roederer, J. Goudsmit, R. Koup and N. J. Sullivan, "Recombinant Adenovirus Serotype 26 (Ad26) and Ad35 Vaccine Vectors Bypass Immunity to Ad5 and Protect Nonhuman Primates against Ebolavirus Challenge,” Journal of Virology, Vol. 85, No. 10, 2011, pp. 4222-4233. doi:10.1128/JVI.02407-10

[26] N. L. Michael, "Rare Serotype Adenoviral Vectors for HIV Vaccine Development,” The Journal of Clinical Investigation, Vol. 122, No. 1, 2012, pp. 25-27. doi:10.1172/JCI60988

[27] J. D. Fuchs, C. Morgan, P. Bart, N. Kochar, N. Frahm, E. Swann, P. Gilbert, S. DeRosa, B. Graham, G. Nabel, H. Liao, B. Haynes and G. Tomaras, "DNA and Recombinant Adenovirus Serotype 35 and 5 Preventive HIV-1 Vaccines with Env a Inserts Elicit Cross-Clade Binding and V1V2 Antibodies," Retrovirology, Vol. 9 No. S2, 2012, p. 136. doi:10.1186/1742-4690-9-S2-P136

[28] M. Rolland, P. T. Edlefsen, B. B. Larsen, S. Tovanabutra, E. Sanders-Buell, T. Hertz, A. C. deCamp, C. Carrico, S. Menis, C. A. Magaret, H. Ahmed, M. Juraska, L. Chen, P. Konopa, S. Nariya, J. N. Stoddard, K. Wong, H. Zhao, W. Deng, B. S. Maust, M. Bose, S. Howell, A. Bates, M. Lazzaro, A. O’Sullivan, E. Lei, A. Bradfield, G. Ibitamuno, V. Assawadarachai, R. J. O’Connell, M. S. deSouza, S. Nitayaphan, S. Rerks-Ngarm, M. L. Robb, J. S. McLellan, I. Georgiev, P. D. Kwong, J. M. Carlson, N. L. Michael, W. R. Schief, P. B. Gilbert, J. I. Mullins and J. H. Kim, "Increased HIV-1 Vaccine Efficacy against Viruses with Genetic Signatures in Env V2," Nature, Vol. 490, No. 7420, 2012, pp. 417-420. doi:10.1038/nature11519

[29] B. F. Haynes, P. B. Gilbert, M. J. McElrath, S. ZollaPazner, G. D. Tomaras, S. M. Alam, D. T. Evans, D. C. Montefiori, C. Karnasuta, R. Sutthent, H. X. Liao, A. L. DeVico, G. K. Lewis, C. Williams, A. Pinter, Y. Fong, H. Janes, A. DeCamp, Y. Huang, M. Rao, E. Billings, N. Karasavvas, M. L. Robb, V. Ngauy, M. S. de Souza, R. Paris, G. Ferrari, R. T. Bailer, K. A. Soderberg, C. Andrews, P. W. Berman, N. Frahm, S. C. De Rosa, M. D. Alpert, N. L. Yates, X. Shen, R. A. Koup, P. Pitisuttithum, J. Kaewkungwal, S. Nitayaphan, S. Rerks-Ngarm, N. L. Michael and J. H. Kim, "Immune-Correlates Analysis of an HIV-1 Vaccine Efficacy trial," The New England Journal of Medicine, Vol. 366, No. 14, 2012, pp. 1275-1286. doi:10.1056/NEJMoa1113425 